\title{
Demography and well-being
}

\author{
Andrew E. Clark ${ }^{1, *}$
}

\section{Abstract}

Demography studies the characteristics of populations. One such characteristic is well-being: this was the subject of the 2019 Wittgenstein Conference. Here, I discuss how objective well-being domains can be summarised to produce an overall wellbeing score, and how taking self-reported (subjective) well-being into account may help in this effort. But given that there is more than one type of subjective wellbeing score, we would want to know which one is "best". We would also need to decide whose well-being counts, or counts more than that of others. Finally, I briefly mention the potential role of adaptation and social comparisons in the calculation of societal well-being.

Keywords: subjective well-being; demography; measurement; policy

How are demography and well-being linked? The answer to this question of course depends on what is meant by both of these terms. Luckily, the definition of one of them appears to be unambiguous. Turning to an increasingly valuable research resource (Wikipedia), we see that demography is defined as "the statistical study of populations, especially human beings". That seems pretty straightforward. Demography and well-being can then interact by considering the well-being of individuals in different population subgroups.

Well-being, on the other hand, can be operationalised in many different ways. One popular way of summarising this concept has been as income, which represents an individual's command over resources. Another has been as access to basic needs (Townsend 1979 and Streeten 1981). A third has been as capabilities (what the individual has the opportunity to achieve: Sen 1985). These are objective definitions of well-being: we observe which individuals possess these resources or capabilities, and which do not.

\footnotetext{
${ }^{1}$ Paris School of Economics - CNRS, Paris, France

${ }^{*}$ Correspondence to: Andrew E. Clark, Andrew.Clark@ens.fr
} 
However, there are many different types of resources available to individuals apart from those that we can easily directly measure in surveys. Moreover, different individuals may value these resources differently. It would seem to be impossible to measure all of the possible resources and their importance at the same time for many thousands of individuals in different populations.

A simple solution to this data collection problem is to outsource it to the individuals themselves. We capture the importance of all of the many resources that individuals find valuable by asking them to provide an overall assessment of how their life is going. This subjective evaluation of one's own life is called subjective well-being. It has a priori much to recommend it: subjective well-being is democratic (individuals themselves, not the researcher, decide what is important), simple to collect (one question may suffice) and easy for respondents to understand (missing values for subjective well-being questions are an order of magnitude smaller than those for income, for example). One common measure of subjective well-being is life satisfaction (although, as we will outline below, there are many others).

Research that uses subjective well-being measures has flourished in recent years (see Clark 2018, for a recent review). Some of these contributions have looked explicitly at the correlations between subjective well-being and various objective well-being measures, which include, using our list above, income (Clark et al. 2008), access to basic needs (Clark and D'Ambrosio 2019) and capabilities (Bruni et al. 2008).

Going back to Wikipedia, the definition of well-being is a broad one: "Well-being, wellbeing, or wellness is the condition of an individual or group. A higher level of well-being means that in some sense the individual's or group's condition is more positive". But the spirit of the term seems to be subjective: the accompanying photo (Note: accessed 12 July 2020) is captioned "Children appearing to experience wellbeing after an art class". The "in some sense" could refer to the dimensions of well-being that the individual finds important. While we as outsiders can conclude that individuals appear to be experiencing well-being, we can also try to determine whether this is indeed the case by actually asking them.

Given the breadth of conditions that might be meant by the term well-being, I applaud the decision of the organisers to focus the 2019 Wittgenstein Conference on demographic aspects of human well-being. What did we learn there? I had three broad reactions to the 36 papers presented over the two days of this conference.

The first is that the gamble to mix demography with well-being paid off. The number of submissions, presentations and attendees surpassed my expectations. My second, and related, reaction is that the conference showed that it is possible to put researchers from different disciplines in the same room without (too much) blood being spilled. I have long believed that one of the positive aspects of the analysis of (subjective) well-being is that it appeals to so many different disciplines across the social sciences. Over time, the cross-disciplinary attention to the topic has produced some common ground in terms of what aspects of well-being we are most interested in, how we measure well-being, and what statistical tools we apply 
to test our hypotheses. My last broad reaction is more policy-oriented: almost every speaker I heard at the conference managed to get their point across in 12 minutes, which led me to wonder why faculty seminars have to be 75 or 90 minutes long.

To move into the details, I noted above that there was "some common ground". When it comes to measurement of well-being, the key word may really be "some". Regarding the objective measures of national well-being, there is, by now, probably a consensus that we should go beyond relying on GDP alone. There is, however, little agreement beyond that point. We have not yet reached a consensus about how many new variables need to be added to GDP in order to summarise societal wellbeing, or about how the different elements of this new index should be weighted. Is crime as important as inequality? How much health am I willing to give up to improve the environment? All political choices to improve one aspect of well-being involve the opportunity cost of not investing in another aspect. Thus, a well-being policy should make explicit the trade-offs between these components. "Traffic-light" indicators that reveal how well a country is doing in a variety of domains (but not how important these domains are compared to each other) do not resolve this problem. One example of a traffic-light indicator is the United Nations' Millennium Development Goals (and their successor, the Sustainable Development Goals). We also see these indicators used to provide health guidance via labelling on food items (for example, see https://www.food.gov.uk/safety-hygiene/check-the-label: But how important is fat relative to salt or sugars?).

The discussions surrounding the measurement of subjective well-being suffer from some of the same types of issues, although here I am rather more optimistic (as summary measures of subjective well-being, such as life satisfaction, should arguably already include all of the aspects of life that the individual finds important). The Wikipedia caption was "appearing to experience well-being"; as I noted above, we can ask people to find out for sure. This is indeed the Wiki definition of subjective well-being as a "self-reported measure of well-being, typically obtained by questionnaire". But there is an embarrassment of riches regarding the different questions that we can ask, a number of which were touched upon at the conference. We could, for example, ask respondents about (i) their life satisfaction (which appears in the main individual-level panel datasets used for subjective well-being, such as the British Household Panel Survey/Understanding Society, the German Socio-Economic Panel, SOEP, and the Household, Income and Labour Dynamics in Australia survey, HILDA); (ii) their evaluation of their life relative to the best and worst they could imagine (the Cantril ladder, as used in the Gallup World Poll); (iii) their psychological health; (iv) whether they experience autonomy, engagement, a sense of meaning, etc., in their life (eudaimonia); or (v) whether they feel/felt happy, bored, sad and so on right now or yesterday (i.e., their mood or affect). Is one of these measures our winner, or should we consider some combination of them?

I suspect that we are all ultimately interested in promoting good policy. The choice of the measure of subjective well-being would not matter if the policy variables on which we can act were correlated in the same way with each of the subjective well-being measures (this is the spirit of the empirical analysis in 
Clark 2016). But the idea of achieving such a correlation across even a small number of key policy variables is probably fanciful. So what is the "right" measure? We are unlikely to be able to make this determination based on polemics alone; we need to put some objective data into the matrix. There may be mileage in looking at how these different subjective well-being measures are correlated with objective neurological and physiological measures (Although this approach then leads us to the question of which of these latter measures best reflects well-being: Is brain activity more or less important than cortisol levels?).

Which brings me to a second option: namely, using beauty contests or cage fights between the different survey measures to see which one best predicts an objective outcome. Individuals wish to maximise their well-being, and will act in order to do so. Using that assumption as a starting point, let us take some panel data and consider some common decisions that individuals make in order to evaluate which subjective well-being measure best predicts these decisions. Among the behaviours we might examine are geographical mobility, marital separation or quitting one's job (for example, Clark 2001 and Senik et al. 2012). At the more aggregate level, it has been suggested that life satisfaction is a good predictor of election results (Ward 2020). But is it possible that other subjective well-being measures perform even better?

Let us now imagine that we have reached an agreement about the best measure of well-being to use. But we are still not out of the woods, as for policy purposes, we also need to decide whose well-being matters more. With respect to objective well-being, societies are often described in terms of both their wealth and how unequally this wealth is distributed. Analogously, we should probably go beyond simply looking at the aggregate subjective well-being in a country, and worry about the level of inequality in the country as well. Some policies may be more (or less) effective in addressing well-being or misery, or the well-being of different groups in a society.

A more subtle point is that in a society, the average well-being will increase, and well-being inequality will decline, if that society experiences greater mortality among those who are the worst-off (something of an analogous argument can be made regarding restrictions on immigration). We need to be explicit about who will be present in the society whose well-being we are evaluating, and who is not there, but could have been. This is a general point that applies equally to the average levels of objective individual outcomes, such as income, education and health.

Formulating good policy requires a lot of knowledge. In our research, many of us have asked about the size of the effect of some variable $Z$ on well-being. When making policy choices, we would also need to know whether we can change $Z$, and how much it costs to change it relative to some other policy variable (some of these considerations appear in Frijters et al. 2020). Moreover, if there is adaptation, the immediate effect of $Z$ on well-being may not continue down the road. And given that there are spillovers between individuals, a policy that makes one individual better off may reduce the well-being of another. Here, the economist's mantra of revealed preference (if I buy something, or, in general, carry out some action, it 
must be in my interest to do so) may not be a good barometer of societal wellbeing. Under adaptation, the fact of wanting something now does not mean that we will still want or enjoy it once we have it. Since we may regret in the future what we are buying/doing now, our current actions are not a good guide to our future well-being (a recent contribution on this point is Odermatt and Stutzer 2019). My current behaviour may be a good measure of my own well-being, but because there are spillovers, it affects the well-being of others as well. When we try to add up individual well-being to produce a national figure, we may find that the purchases made by each individual do not increase aggregate well-being if the positive effect on the individuals making the purchases is potentially cancelled out by the lower well-being of others. Both adaptation and spillovers are taken into account in simple subjective well-being scores: your adaptation to a new job or a new house will be reflected in a gradual drop in well-being back towards its initial level, while any spillovers will appear directly in the well-being scores of those who are harmed by your actions.

Once the most appropriate definition of well-being is sorted out, we can move on to some fundamental questions, such as are some populations or areas doing better than others? If well-being differentials are indeed found, do they reflect the (age/sex/ethnicity/education) composition of the population, or some underlying (un)attractive feature? To what extent do well-being differentials cause individuals to move between areas? And are there spillovers between areas, such that factors like criminality or a good environment in an area affect not only those who live in that area, but those who live nearby as well? This is a fascinating time in which to be carrying out this kind of research, and conferences such as the conference on the link between demography and well-being organised by the Wittgenstein Centre help to pave the way forward.

\section{Acknowledgments}

I am grateful to the editors for their feedback, and to Conchita D'Ambrosio for useful discussions.

\section{References}

Bruni, L., F. Comim and M. Pugno (eds) 2008. Capabilities and happiness. Oxford: Oxford University Press.

Clark, A. E. 2001. What really matters in a job? Hedonic measurement using quit data. Labour Economics 8(2): 223-242. https://doi.org/10.1016/S0927-5371(01)00031-8

Clark, A. E. 2016. SWB as a measure of individual well-being. In: Oxford handbook of well-being and public policy, eds M. Adler and M. Fleurbaey. Oxford: Oxford University Press. https://doi.org/10.1093/oxfordhb/9780199325818.013.17 
Clark, A. E. 2018. Four decades of the economics of happiness: Where next? Review of Income and Wealth 64(2): 245-269. https://doi.org/10.1111/roiw.12369

Clark, A. E. and C. D'Ambrosio 2019. Living conditions and basic needs: Evidence from African Countries. South African Journal of Economics 87(2): 91-109. https://doi.org/10. 1111/saje.12219

Clark, A. E., P. Frijters and M. Shields 2008. Relative income, happiness and utility: An explanation for the Easterlin paradox and other puzzles. Journal of Economic Literature 46(1): 95-144. https://doi.org/10.1257/jel.46.1.95

Frijters, P., A. E. Clark, C. Krekel and R. Layard 2020. A happy choice: Wellbeing as the goal of government. Behavioural Public Policy 4(2): 126-165. https://doi.org/10.1017/ bpp.2019.39

Odermatt, R. and A. Stutzer 2019. (Mis-)predicted subjective well-being following life events. Journal of the European Economic Association 17(1): 245-283. https://doi.org/10.1093/ jeea/jvy005

Sen, A. 1985. Commodities and capabilities. Amsterdam: North-Holland.

Senik, C., H. Stichnoth and C. Guven 2012. You can't be happier than your wife. Happiness Gaps and Divorce. Journal of Economic Behavior and Organization 82(1): 110-130. https://doi.org/10.1016/j.jebo.2012.01.003

Streeten, P. 1981. First things first: Meeting basic human needs in developing countries. New York: Oxford University Press.

Townsend, P. 1979. Poverty in the United Kingdom. Harmondsworth: Penguin Books.

Ward, G. 2020. Happiness and voting: Evidence from four decades of elections in Europe. American Journal of Political Science 64(3): 504-518. https://doi.org/10.1111/ajps.12492

Open Access This article is published under the terms of the Creative Commons Attribution 4.0 International License (https://creativecommons.org/licenses/by/4.0/) that allows the sharing, use and adaptation in any medium, provided that the user gives appropriate credit, provides a link to the license, and indicates if changes were made. 